\title{
Sebaceous carcinoma of the right palate: case report and literature review
}

\author{
Qun Lu" ${ }^{1 \#}$, Xiao-Yue Fu ${ }^{2 \#}$, Yi Huang ${ }^{1}$ \\ ${ }^{1}$ Department of stomatology, Sichuan Academy of Medical Sciences and Sichuan Provincial People's Hospital, Chengdu, China; ${ }^{2}$ Department of \\ Oncology, Wenjiang District People's Hospital, Chengdu, China \\ "These authors contributed equally to this work. \\ Correspondence to: Yi Huang, D.D.S. MD. Sichuan Academy of Medical Sciences and Sichuan Provincial People's Hospital, 32 West Second Section \\ First Ring Road, Chengdu, China. Email: maohuangyi@163.com.
}

\begin{abstract}
Considering the low incidence rates of primary sebaceous carcinoma (SC) of extraorbital sites, let alone those occur in intraoral sites, clinicopathological characteristics and histogenesis are not fully understood. In the present case, a maxillary mass was presented and a low-grade malignant tumor was suspected according to the CT scans, preoperative FNA, and clinical conditions. Other carcinomas, including acinar cell carcinoma (ACC), basaloid cell carcinoma (BCC), SCC, mucoepidermoid carcinoma, and epithelial-myoepithelial carcinoma (EMC), were also considered before surgery. Due to the rare occurrence of SC and no preoperative suspects, a fresh sample was not kept. Sadly, thus cause those special stains (e.g., Oil Red O and Sudan IV) which form the primary basis for a diagnosis of SC in academic circles were missing. A comprehensive literature review identified only 10 cases of intraoral SC, of which the primary sites reported in the English literature were the buccal mucosa, mouth floor, upper labial mucosa, and tongue. Due to an absence of specific biomarkers and simulated characters, histochemistry and immunohistochemistry such as PAS, CK, EMA, p63, p53, S-100, calponin, CD117, Ki-67, a-SMA, and AR form the diagnostic standard of SC. Postoperative immunohistochemistry of our case showed S100(-), Ki67(-), calponin(-), CD117(-), CK20(-), PAS(-), AR(+), CK(+), CK5/6(+), P53(+), P63(+), a-SMA (+). Thus the diagnosis of SC was finally made. Through discussing the findings of our case and reviewing literature, we present the histological features and discuss possible outstanding biomarkers of this neoplasm.
\end{abstract}

Keywords: Sebaceous carcinoma (SC); oral mucosa; diagnosis; case report

Submitted Feb 10, 2021. Accepted for publication May 19, 2021.

doi: $10.21037 /$ gs-21-218

View this article at: http://dx.doi.org/10.21037/gs-21-218

\section{Introduction}

Known as Fordyce granules, sebaceous glands in the oral mucosa are widely found in approximately $80 \%$ of adults' mouths $(1,2)$. Due to the high incidence rate, Fordyce granules have been considered a normal anatomic variation (1). Varying in numbers, these granules always appear as small asymptomatic yellow-white colored papules or granules in the oral mucosa (e.g., the buccal mucosa and upper lip). These granules are common in the oral mucosa, conversely, intraoral sebaceous neoplasms are very uncommon. It seems like these intraoral sebaceous glands rarely give rise to a variety of sebaceous neoplasms (3-6), such as sebaceous carcinoma (SC).

According to clinical data, SC appears to have a specific anatomic preference for the ocular region, especially the eyelids. It has been estimated that approximately $25 \%$ of SC occur in extra-orbital sites, approximately $70 \%$ of which are in the head and neck regions $(7,8)$. Intraoral SC is an exceedingly rare neoplasm. To date, only 10 cases appear to have been reported in the English literature. It has been reported that SC occurs in the buccal mucosa, labial mucosa, anterior mouth floor, and tongue (see Table 1) (3-6,9-14). This paper reports the first intraoral case of SC 
Table 1 Reported cases of primary intraoral sebaceous carcinoma

\begin{tabular}{|c|c|c|c|c|}
\hline Case & Author/patient age & Year & Anatomic location & Treatment \\
\hline $\begin{array}{l}\text { Sebaceous carcinoma of buccal mucosa. } \\
\text { Report of a case }\end{array}$ & Liu et al./68 & 1997 & Buccal mucosa & Excision \\
\hline Intraoral sebaceous carcinoma & Handschel et al./80 & 2003 & Anterior floor of the mouth & Excision \\
\hline $\begin{array}{l}\text { Intraoral sebaceous carcinoma metastatic } \\
\text { to the lung and subcutis: case report and } \\
\text { discussion of the literature }\end{array}$ & Rowe et al./76 & 2014 & Anterior maxillary gingiva & Excision \\
\hline $\begin{array}{l}\text { Sebaceous carcinoma of the maxillary gingival: } \\
\text { first reported case involving the gingival }\end{array}$ & Wetzel et al./75 & 2015 & Maxillary gingiva & Excision \\
\hline $\begin{array}{l}\text { Primary sebaceous carcinoma of the tongue. } \\
\text { Med Mol Morphol. } 8\end{array}$ & Oshiro et al. /66 & 2010 & Tongue and dorsum & $\begin{array}{l}\text { Intra-arterial } \\
\text { chemotherapy/ } \\
\text { radiation }\end{array}$ \\
\hline Intraoral sebaceous carcinoma & Gomes et al./55 & 2007 & Mandible & $\begin{array}{l}\text { Excision, } \\
\text { chemotherapy, } \\
\text { radiotherapy }\end{array}$ \\
\hline Intraoral sebaceous carcinoma & Abuzeid et al./11 & 1996 & Buccal mucosa & Excision \\
\hline
\end{tabular}

involving the soft palate. It also provides a brief review of the literature, and discusses the histogenesis, differential diagnosis, and clinicopathological features of this disease.

We present the following article in accordance with the CARE reporting checklist (available at http://dx.doi. org/10.21037/gs-21-218).

\section{Case presentation}

All procedures performed in studies involving human participants were in accordance with the ethical standards of the institutional and/or national research committee(s) and with the Helsinki Declaration (as revised in 2013). Written informed consent was obtained from the patient for publication of this study and any accompanying image.

In April 2015, a 62-year-old female presented with a growth in her palatal, which had first appeared approximately one year ago. Initially, a small nodule $(0.5 \mathrm{~cm} \times 0.5 \mathrm{~cm})$ appeared beneath the mucosa; however, it gradually grew to its present size of $2.0 \mathrm{~cm} \times 1.5 \mathrm{~cm}$, and had become painful. The patient had received antibiotic treatment, but the volume of the growth had not reduced, and the pain was not relieved. She had no similar growth elsewhere on her body, and had undergone no surgical excision previously. Additionally, no histories of any similar diseases had been discovered in her family. She did not use alcohol or tobacco.

A computerized tomography (CT) scan showed a mass, $2 \mathrm{~cm} \times 1.3 \mathrm{~cm}$ in size, beneath the hard palate, and the adjacent bones showed oppressive absorption (see Figure 1). Upon physical examination, a markedly exophytic, irregularly shaped mass, $2 \mathrm{~cm} \times 3 \mathrm{~cm}$ in size, was located at the juncture of the soft and hard palates. The lesion was mildly tender upon palpation, but Fordyce granules were not noticed in the intraoral lesions, and no regional lymphadenopathy was observed in the drainage area. A further CT scan showed a soft mass, no more than $1.8 \mathrm{~cm}$ $\times 2.5 \mathrm{~cm}$ in size, in the right soft palate, and the adjacent maxillary sinus bone was absorbed. A fine-needle aspiration (FNA) and histological examination were then performed, no valuable cells were detected. A diagnosis could not be made; however, a low-grade malignant tumor was suspected 

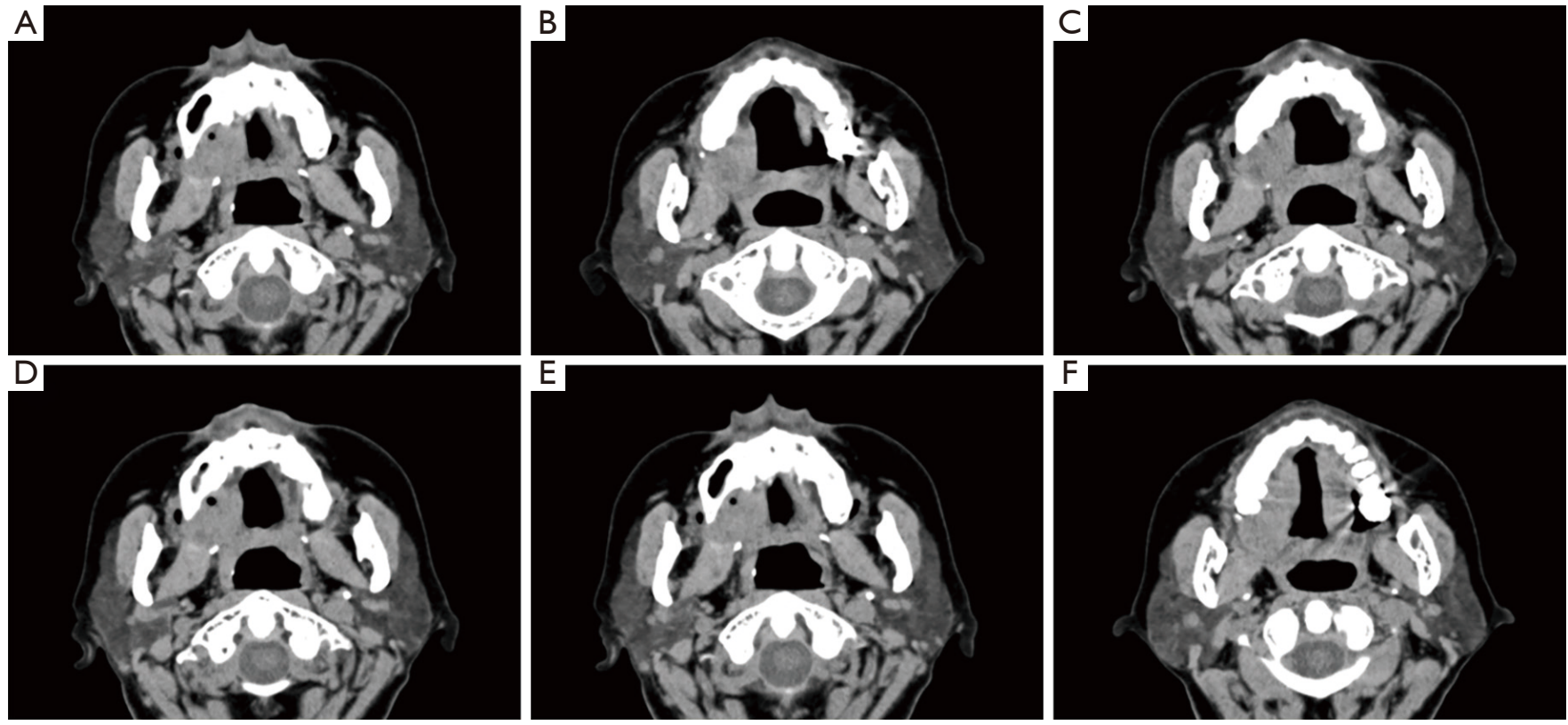

Figure 1 CT images of the mass, which was located in the right maxilla near the alveolar bone where nearby bone had been absorbed. CT, computerized tomography. From (A) to (F) show several CT planes in a row to reflect the location, size and nearby anatomical structure of the lesion (preoperative and intraoperative intraoral photos were not taken because the disease was so rare before surgery).

based on the CT findings and clinical conditions.

During surgery, the tumor was found to have invaded the underlying bone, but there was no definite evidence of angiolymphatic or perineural invasion. The tumor was resected along with a $1 \mathrm{~cm}$ range of healthy tissue, including tissue from the alveolar ridge of the upper jaw, part of the hard palate, and some muscle. During the surgery, a frozensection examination indicated that squamous epithelial sections were negative for tumor, and the oroantral fistula was covered with a local flap.

\section{Discussion}

The palatal specimen contained an ovoid mass with a maximum size of $2.5 \mathrm{~cm}$. Grossly, the tumor was fulvescentbrown in color with nest invasive cells (see Figure $2 A$ ). Under a low-power lens, the nests of large polygonal cells were observed to have centrally located prominent nuclei and the clear cytoplasmic vacuoles were surrounded by the basaloid cells, indicating sebaceous differentiation (see Figure 2B,C,D). Due to compression from the intracytoplasmic vacuoles, the scattered nuclei were observed to have a scalloped appearance. Further, typical and atypical mitotic images were observed throughout the lesion (see Figure 2E,F).

Histopathology revealed an inconclusive pattern but strongly suggested that malignancy originated in the salivary gland. This was a remarkable indicator of SC; however, squamous cell carcinoma (SCC) and mucoepidermoid carcinoma were originally considered in the histological differential diagnosis. A periodic acidSchiff (PAS) stain and immunohistochemical stain for creatine kinase (CK), epithelial membrane antigen (EMA), p63, p53, S-100, calponin, CD117, Ki-67, a-SMA, and androgen receptor (AR) were performed. In general, the staining patterns in this case were $\operatorname{PAS}(-), \operatorname{EMA}(+), \mathrm{AR}(+)$ (see Figure $3 A, B, C$ ). Other biomarker staining patterns were calponin(-), CD117(-), CK(+), CK20(-), CK5/6(+), Ki67(+5\%), p53(+40\%), p63(+), S-100(-), and a-SMA(+) (see Figure $3 D, E, F, G, H, I, \mathcal{F}, K, L, M)$. Based on the histological examination and immunohistochemical studies, a diagnosis of intraoral SC was finally confirmed

Histologically, sebaceous neoplasms of the salivary glands are divided into the following 5 categories: sebaceous adenoma, sebaceous lymphadenoma, SC, sebaceous lymph adenocarcinoma, and sebaceous differentiation in other tumors (15). By definition, SC is a cytologically and/or architecturally malignant tumor characterized by exclusive 

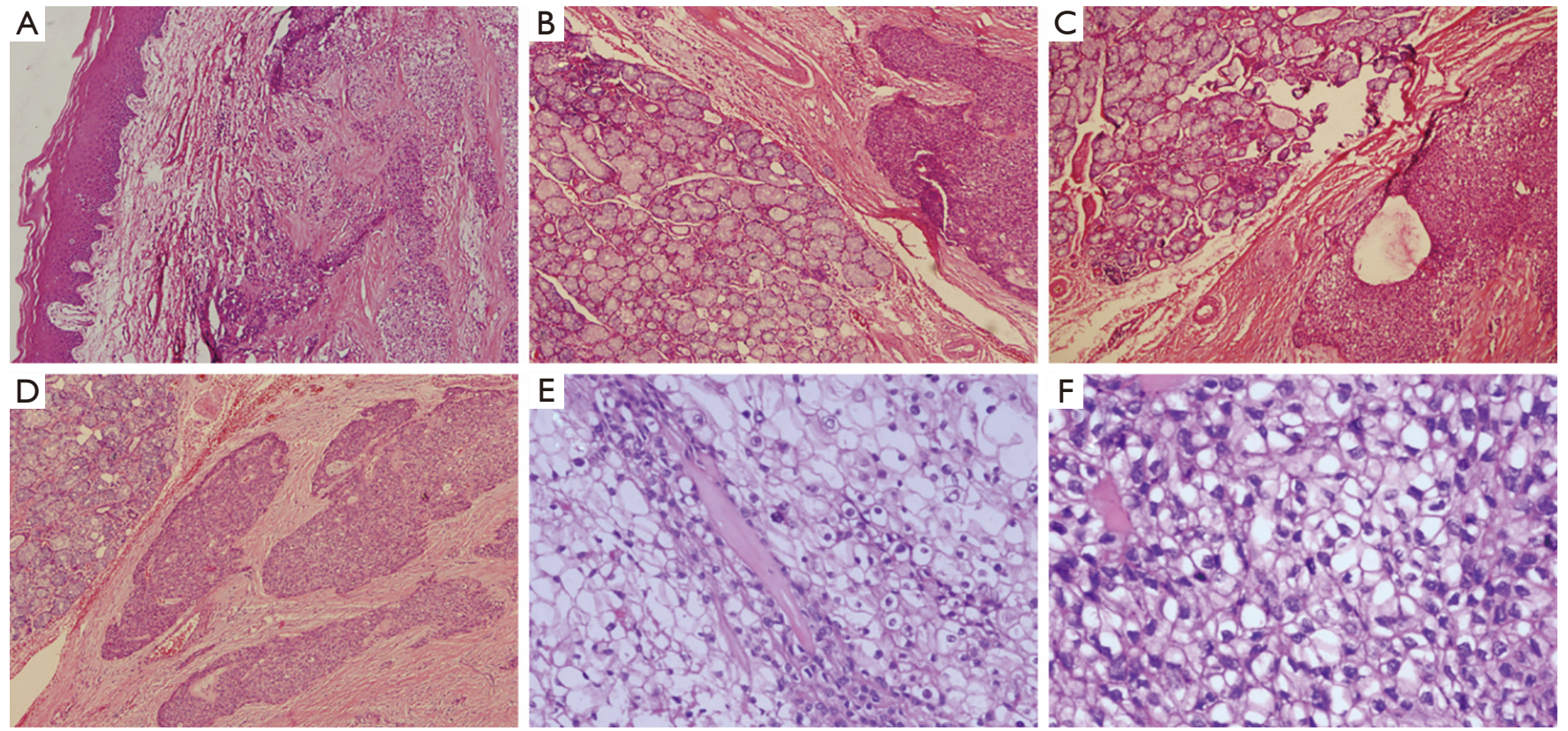

Figure 2 Histological appearance of sebaceous carcinoma. Low magnification shows surface mucosa with infiltrating nests, and sheets of ovoid epithelial cells with abundant clear to eosinophilic cytoplasm (H\&E A: original magnification $\times 40$ ). High magnification shows malignant cellular nests with cytoplasmic vacuolization of central and peripheral large nuclei that were surrounded by basaloid cells and acinar cells $(H \& E$ B,C,D: original magnification $\times 100)$. Intracytoplasmic vacuoles, prominent nucleoli and mitotic images were observed within the lesioned cells (H\&E E: original magnification-200; F: original magnification $\times 400$ ).

sebocyte differentiation (16). It commonly occurs in the head and neck regions (75\%), especially the eyelids, but infrequently appears on the scalp or other areas of the face. Conversely, extraocular maxillofacial SC occurs much less frequently, and most reported cases have involved the major salivary glands (i.e., the parotid glands) (17). A comprehensive literature review identified only 10 cases of intraoral SC, of which the primary sites reported in the English literature were the buccal mucosa, mouth floor, upper labial mucosa, and tongue (see Table 1). Thus, this appears to be the first case of SC involving the soft palate.

The pathogenesis of intraoral SC is mysterious and requires further elucidation. Some scholars view that the primary occurrence of SC is associated with the salivary tissue in the mouth cavity; sebaceous differentiation of the salivary tissue has been found in as many as $42 \%$ of the common parotid glands (18). Conversely, it has also been hypothesized that intraoral SC might be caused by the malignant transformation of ectopic sebaceous glands, also known as Fordyce granules (3-6). Notably, it has been theorized that sebaceous cells are contained in $10-40 \%$ of the parotid glands and $6-10 \%$ of the submandibular glands
$(16,19,20)$. Somewhat confusingly, Fordyce granules have been discovered in $80 \%$ of oral mucosa, but SC develops much more frequently in the major salivary glands than in the oral cavity $(1,2)$. Further, sebaceous differentiation has been noted in squamous epithelium due to inflammation (16). Fordyce granules are common in the oral mucous membrane; however, somewhat strangely, SC is very rare in the oral cavity. Notably, Fordyce granules were not found in this case. Given these findings, it appears that there might be another possible cause for intraoral SC. However, as so few cases have been reported, the precise pathogenesis remains unclear.

Due to an absence of specific biomarkers and simulated characters, histochemistry and immunohistochemistry form the diagnostic standard of SC. Thus far, microscopic examinations aided by special stains (e.g., Oil Red O and Sudan IV) form the primary basis for a diagnosis of SC in academic circles. In the present case, a low-grade malignant tumor was suspected according to the CT scans, preoperative FNA, and clinical conditions. Other carcinomas, including acinar cell carcinoma (ACC), basaloid cell carcinoma (BCC), SCC, mucoepidermoid carcinoma, 


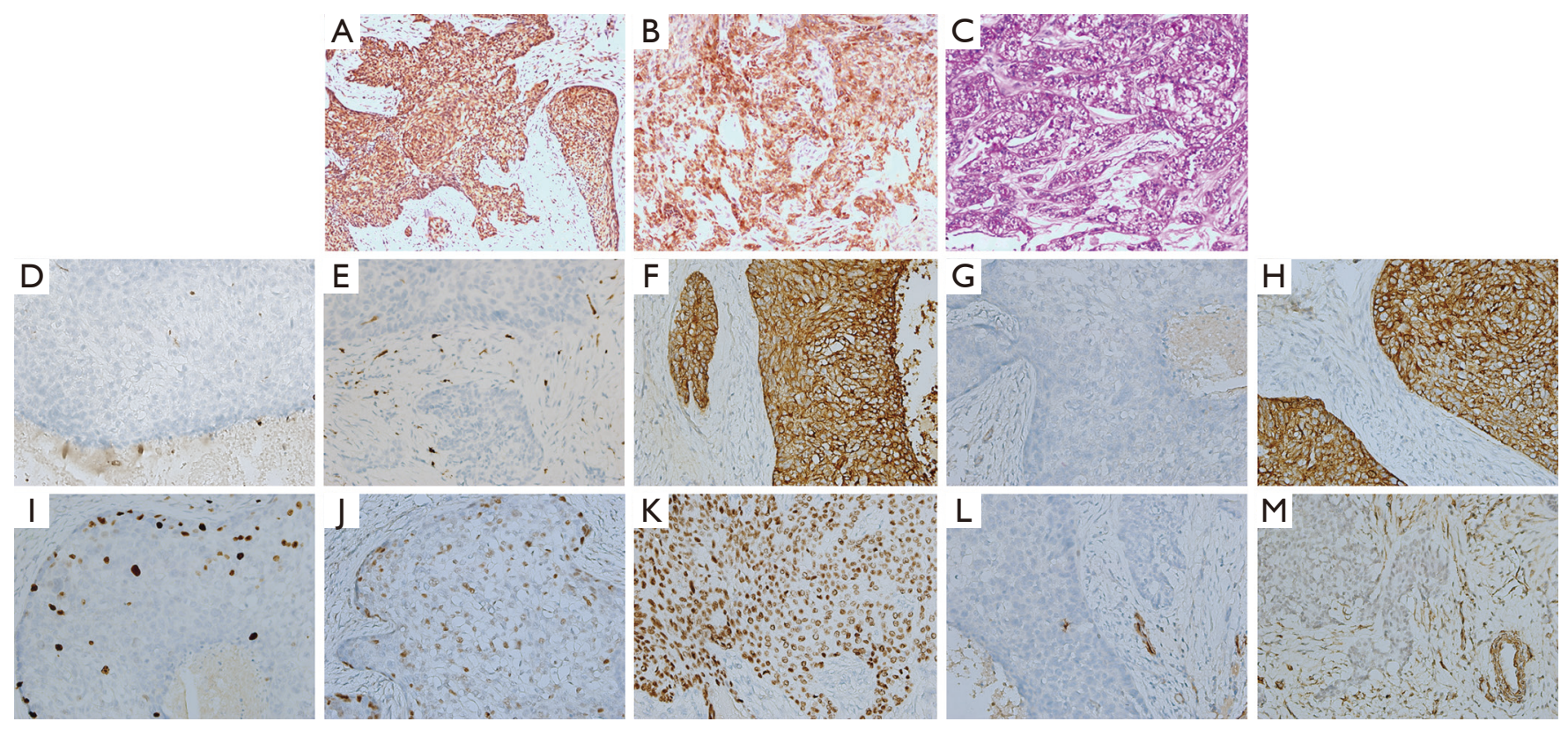

Figure 3 Immunohistochemical staining for several immunohistochemical biomarkers. (A) SC cells were negative for PAS stains; (B) sebaceous cells demonstrated membranous and cytoplasmic reactivity with EMA; (C) the neoplastic basaloid cells and sebaceous cells exhibited strong nuclear reactivity with the AR antibody; (D) SC cells were negative for calponin; (E) SC cells were negative for CD117; (F) SC cells were positive for CK; (G) SC cells were negative for CK20; (H) SC cells were positive for CK5/6(+); (I) SC cells were mostly negative for Ki-67; (J) SC cells were partially positive for P53; (K) SC cells were positive for P63; (L) SC cells were negative for S-100; (M) SC cells were positive for a-SMA (the original magnification of all images was $\times 100$ ). SC, sebaceous carcinoma; PAS, periodic acid-Schiff; EMA, epithelial membrane antigen; CK, creatine kinase.

and epithelial-myoepithelial carcinoma (EMC), were also considered before surgery. Massive vacuolated cells were seen in the hematoxylin and eosin stain (H\&E) section, which were normal in clear cell melanoma, SCC with clear cell change, SC, and mucoepidermoid carcinoma. The postoperative histological examination did not specifically lead to the identification of the type of this malignancy, but it was strongly suggestive of SC.

In the present case, due to the rare occurrence of the tumor and no preoperative suspects, a fresh sample was not kept, causing the missed stain of Oil Red O and Sudan IV. Due to similar conditions arising in other cases and tests failing to completely solve diagnostic dilemmas, timely diagnoses cannot always be made (21-23). In such cases, several other immunohistochemical markers can be assessed to determine their potential roles in the process of the SC and differential diagnoses, such as PAS, CK, EMA, p63, p53, S-100, calponin, CD117, Ki-67, a-SMA, and AR. As Mulay showed, $\mathrm{Ki}-67, \mathrm{P} 53$ and $\mathrm{CK}$ were positive in the cases of SC, SCC, and BCC (24). However, in the present case, the tumor was positive for $\mathrm{CK}, \mathrm{CK} 5 / 6$, and $\mathrm{P} 53$, but negative for CK20 and $\mathrm{Ki}-67$. As the diagnostic use of CK and $\mathrm{Ki}-67$ is controversial, other proofs were needed to verify a final diagnosis.

Rather than believing that basaloid and sebaceous cells show powerful nuclear immunoreactivity with ARs and separate membranous and cytoplasmic reactivity with EMAs, Carolina et al. viewed ARs as a better marker of sebaceous differentiation than EMA. Additionally, studies have also shown that SC can be negative for PAS and S100 but positive for EMA, and thus can be distinguished from other tumors (14,24-26). To replicate those test results, the biomarkers of PAS, S100, AR, and EMA were tested. Similar findings were observed in the present case (i.e., that PAS and S100 were negative). Notably, the postoperative immunohistochemical test showed that the tumor cells in the present case indicated positivity for both EMA and AR, which confirmed that the vacuolated clear cells were not mucus cells or squamous cells containing rich glycogen. Based on these findings, SCC, clear cell melanoma, and BCC were precluded before the final SC diagnosis.

The rarity of the neoplasm indicates that it is necessary 
to establish optimal treatments. In most cases, surgical treatments have been adopted. Postoperative irradiation, chemotherapy, and immunosuppressive treatment are controversial; however, they have also been adopted in metastasis cases. As Table 1 shows, surgery was undertaken in 8 cases, while assisted chemotherapy and/or radiotherapy were administered in the remaining cases.

\section{Conclusions}

An infrequent SC in a patient's palate was observed. Radical surgery was carried out. A preoperative diagnosis indicated a myoepithelial tumor or possibly a mucoepidermoid carcinoma. The infrequency and unfamiliarity of SC resulted in the loss of fresh samples, and created difficulties in the differential diagnosis. The histogenesis, differential diagnosis, and clinicopathologic conditions of this disease in the literature were reviewed. As a rare malignant tumor, SC should be distinguished from other tumors full of vacuolated clear cells. Additionally, all of the possible useful biomarkers, such as Ki-67, P53, CK, PAS, S-100, EMA, and AR, were listed to help verify the diagnosis. Previous cases in the English-literature and the present case suggest that in addition to stains of Oil Red O and Sudan IV, positive immunohistochemical stains of Ki-67, P53, EMA, and AR and negative immunohistochemical stains of PAS and S100 can also be helpful in verifying a diagnosis of SC. Notably, the role of $\mathrm{CK}$ in the differential diagnosis was ambiguous. Postoperative chemotherapy and radiotherapy were not adopted in the present case, as the postoperative pathology showed negative tumor margins, and there was no evidence of lymph node metastasis, the patient was relatively satisfied with the surgery.

\section{Acknowledgments}

Funding: None.

\section{Footnote}

Reporting Checklist: The authors have completed the CARE reporting checklist. Available at http://dx.doi.org/10.21037/ gs-21-218

Conflicts of Interest: All authors have completed the ICMJE uniform disclosure form (available at http://dx.doi. org/10.21037/gs-21-218). The authors have no conflicts of interest to declare.
Ethical Statement: The authors are accountable for all aspects of the work in ensuring that questions related to the accuracy or integrity of any part of the work are appropriately investigated and resolved. Written informed consent was obtained from the patient for publication of this study and any accompanying image. All procedures performed in studies involving human participants were in accordance with the ethical standards of the institutional and/or national research committee(s) and with the Helsinki Declaration (as revised in 2013).

Open Access Statement: This is an Open Access article distributed in accordance with the Creative Commons Attribution-NonCommercial-NoDerivs 4.0 International License (CC BY-NC-ND 4.0), which permits the noncommercial replication and distribution of the article with the strict proviso that no changes or edits are made and the original work is properly cited (including links to both the formal publication through the relevant DOI and the license). See: https://creativecommons.org/licenses/by-nc-nd/4.0/.

\section{References}

1. Gorsky M, Buchner A, Fundoianu-Dayan D, et al. Fordyce's granules in the oral mucosa of adult Israeli Jews. Community Dent Oral Epidemiol 1986;14:231-2.

2. Olivier JH. Fordyce granules on the prolabial and oral mucous membranes of a selected population. SADJ 2006;61:072-4.

3. Damm DD, O'Connor WN, White DK, et al. Intraoral sebaceous carcinoma. Oral Surg Oral Med Oral Pathol 1991;72:709-11.

4. Liu CJ, Chang KW, Chang RC. Sebaceous carcinoma of buccal mucosa. Report of a case. Int J Oral Maxillofac Surg 1997;26:293-4.

5. Handschel J, Herbst H, Brand B, et al. Intraoral sebaceous carcinoma. Br J Oral Maxillofac Surg 2003;41:84-7.

6. Alawi F, Siddiqui A. Sebaceous carcinoma of the oral mucosa: case report and review of the literature. Oral Surg Oral Med Oral Pathol Oral Radiol Endod 2005;99:79-84.

7. Pickford MA, Hogg FJ, Fallowfield ME, et al. Sebaceous carcinoma of the periorbital and extraorbital regions. Br J Plast Surg 1995;48:93-6.

8. Wick MR, Goellner JR, Wolfe JT, et al. Adnexal carcinomas of the skin. II. Extraocular sebaceous carcinomas. Cancer 1985;56:1163-72.

9. Rowe ME, Khorsandi AS, Urken GR, et al. Intraoral sebaceous carcinoma metastatic to the lung and subcutis: 
Case report and discussion of the literature. Head Neck 2016;38:E20-4.

10. Wetzel S, Pacelli P, Reich R, et al. Sebaceous carcinoma of the maxillary gingival: First reported case involving the gingiva. Oral Surg Oral Med Oral Pathol Oral Radiol 2015;120:e1-3.

11. Li TJ, Kitano M, Mukai H, et al. Oral sebaceous carcinoma: report of a case. J Oral Maxillofac Surg 1997;55:751-4.

12. Wang H, Yao J, Solomon M, et al. Sebaceous carcinoma of the oral cavity: a case report and review of the literature. Oral Surg Oral Med Oral Pathol Oral Radiol Endod 2010;110:e37-40.

13. Oshiro H, Iwai T, Hirota $M$, et al. Primary sebaceous carcinoma of the tongue. Med Mol Morphol 2010;43:246-52.

14. Gomes CC, Lacerda JC, Pimenta FJ, et al. Intraoral sebaceous carcinoma. Eur Arch Otorhinolaryngol 2007;264:829-32.

15. Gnepp DR. My journey into the world of salivary gland sebaceous neoplasms. Head Neck Pathol 2012;6:101-10.

16. Kyllo RL, Brady KL, Hurst EA. Sebaceous carcinoma: review of the literature. Dermatol Surg 2015;41:1-15.

17. Batsakis JG, Littler ER, Leahy MS. Sebaceous cell lesions of the head and neck. Arch Otolaryngol 1972;95:151-7.

18. Knackstedt T, Samie FH. Sebaceous Carcinoma: A Review

Cite this article as: Lu Q, Fu XY, Huang Y. Sebaceous carcinoma of the right palate: case report and literature review. Gland Surg 2021;10(5):1819-1825. doi: 10.21037/gs-21-218 of the Scientific Literature. Curr Treat Options Oncol 2017;18:47.

19. Gnepp DR, Brannon R. Sebaceous neoplasms of salivary gland origin. Report of 21 cases. Cancer 1984;53:2155-70.

20. Carlson ER, Schlieve T. Salivary Gland Malignancies. Oral Maxillofac Surg Clin North Am 2019;31:125-44.

21. Shields JA, Demirci H, Marr BP, et al. Sebaceous carcinoma of the eyelids: personal experience with 60 cases. Ophthalmology 2004;111:2151-7.

22. Doxanas MT, Green WR. Sebaceous gland carcinoma. Review of 40 cases. Arch Ophthalmol 1984;102:245-9.

23. Plaza JA, Mackinnon A, Carrillo L, et al. Role of immunohistochemistry in the diagnosis of sebaceous carcinoma: a clinicopathologic and immunohistochemical study. Am J Dermatopathol 2015;37:809-21.

24. Mulay K, White VA, Shah SJ, et al. Sebaceous carcinoma: clinicopathologic features and diagnostic role of immunohistochemistry (including androgen receptor). Can J Ophthalmol 2014;49:326-32.

25. Ho CK. Sebaceous Carcinoma. Hong Kong Dermatology \& Venereology Bulletin 2002;10:129-32.

26. Oh SH Lee SS, Seo YJ. P75 Extraocular Sebaceous Carcinoma Treated with Wide Excision and Island Flap. Melanoma Res 2010;20:e76-77.

(English Language Editor: L. Huleatt) 